\title{
Enoturismo: experiências e sensações no Vale dos Vinhedos (RS)
}

\author{
Wine Tourism: experiences and sensations in the Vale dos Vinhedos (RS)
}

Turismo del Vino: experiencias y sentimientos en el Vale dos Vinhedos (RS)

\author{
Hernanda Tonini ${ }^{1}$ \\ Joice Lavandoski ${ }^{2}$
}

\begin{abstract}
Resumo
Consumir, na atualidade, faz parte do cotidiano dos indivíduos. Diferentes formas e produtos são disponibilizados às pessoas para que possam adquirir e desfrutar de benefícios, satisfazer necessidades; necessidades estas que podem estar relacionadas ao ser ou, de modo cada vez mais crescente, ao ter. Ao abordar o termo "produto", não são apenas aspectos concretos, materiais ou palpáveis, que entram em pauta. Vive-se a tendência de consumir emoções e a atividade turística obtém destaque quando o tema é emoção e experiência única. A experiência de degustar temperos e pratos típicos, vinhos e paisagens, vão além do consumo de um simples produto turístico, ultrapassando barreiras culturais e limites econômicos. Através da pesquisa realizada no Vale dos Vinhedos, importante destino enoturístico do país, foi possível identificar que as viagens equivalem a momentos repletos de sensações.
\end{abstract}

Palavras-chave: experiência; sensações; turismo; enoturismo; Vale dos Vinhedos.

\section{Abstract}

To consume, actually, is a part of the daily life. Different forms and products are available to people, who can acquire and enjoy benefits, to meet needs that may be related to way of being, and later, the way of having. Consequently, the term "product" is not only about the specific aspects, material or tangible ones. The consumer emotions and specifically in the tourism field get highlighted when the theme is to try unique experiences. To experience new seasoned and tasty typical dishes, wines and scenery are beyond the mere consumption of a tourism product, overcoming cultural barriers and economic limits. Through research conducted in the Vale dos Vinhedos, a wine tourism important destination in this country, it

\footnotetext{
${ }^{1}$ Bacharel em Turismo (UNISUL), Mestre em Turismo (UCS) e doutoranda em Desenvolvimento Rural (UFRGS). Docente do Instituto Federal de Educação, Ciência e Tecnologia do Rio Grande do Sul (IFRS) e pesquisadora em turismo, com ênfase em enoturismo. Email: hernanda.tonini@restinga.ifrs.edu.br.

${ }^{2}$ Bacharel e Mestre em Turismo pela Universidade de Caxias do Sul. Professora de Turismo. Colunista e pesquisadora em Turismo com área de concentração no Enoturismo, Desenvolvimento Regional e Gestão. Email: joicelavandoski@yahoo.com.br.
} 
was possible to identify that certain trips are the equivalent of moments that are full of feelings and sensations.

Keywords: experience; sensations; tourism; wine tourism; Vale dos Vinhedos.

\section{Resumen}

Consumir en la actualidad, forma parte de la vida cotidiana. Diferentes formas y productos están disponibles para personas que pueden adquirir y disfrutar de los beneficios, para satisfacer las necesidades; aquellas que pueden estar relacionadas con el ser o, de manera cada vez más creciente, el tener. Al abordar el término "producto" no son solo aspectos especificos, material o tangible, que vienen en la agenda. Se vive la tendencia de consumo de las emociones y el turismo se resalta cuando el tema es la emoción y la experiencia. La experiencia de degustar platos típicos, vinos y paisajes, se vá más allá del consumo simples de un producto turístico, excedendo las barreras culturales y las limitaciones económicas. A través de investigaciones realizadas en el Vale dos Vinhedos, importante destino enoturístico en el país, se identificó que los viajes son equivalentes a momentos llenos de sensaciones.

Palabras clave: experiencia; sensaciones; turismo; turismo del vino.

\section{Introdução}

Frente as poucas pesquisas em enoturismo, esta temática objetiva avançar com os estudos sobre o enoturismo, proporcionando reflexões norteadoras para pesquisadores e estudantes na área, como também para a esfera pública e privada interessada em compreender as necessidades, os desejos e a satisfação dos turistas num destino que tem como atrativo principal a uva e o vinho.

O Vale dos Vinhedos, localizado na Serra Gaúcha, no Estado do Rio Grande do Sul, é a principal rota enoturística do Brasil, que proporciona aos turistas experiências marcantes como a degustação de vinhos, a gastronomia típica italiana, a paisagem, o clima de paz e a tranquilidade que paira na região.

No intuito de melhor compreender a relação existente entre turismo e a experiência das viagens gastronômicas, o presente artigo apresenta os resultados de pesquisas realizadas com os turistas em vinícolas do Vale dos Vinhedos. Propõe reflexões quanto ao consumo turístico e as experiências subjetivas de um turista no Vale dos Vinhedos. 
Um dos motivos para a realização da pesquisa foi a implantação do Projeto Economia da Experiência - Vivências na Região Uva e Vinho, realizado pelo Ministério do Turismo, em parceria com o Sebrae Nacional e o Sindicato de Hotéis, Restaurantes, Bares e Similares da Região Uva e Vinho. Além do interesse particular das pesquisadoras com o enoturismo e o universo que o cerca.

\section{Viajando e Consumindo Sensações}

Se na pré-história os deslocamentos realizados ocorriam basicamente motivados pela busca de sustento, na atualidade os motivos que levam as pessoas a se deslocar, tornam a atividade um tanto mais complexa. Viajar tornou-se um consumo para um número cada vez maior de indivíduos da sociedade contemporânea, que vai muito além do simples ato de adquirir determinado produto ou serviço. Optar entre este ou aquele produto deixou de ser apenas uma questão de satisfazer necessidades reais para tornar-se também um hábito que visa à satisfação de uma série de desejos. Para muitos, a satisfação está na própria necessidade de comprar algo, seja supérfluo ou realmente útil.

$\mathrm{Na}$ ampla gama de necessidades que precisam ser satisfeitas constantemente, encontram-se aquelas de cunho emocional. Viajar é um produto cuja procura torna-se cada vez maior, caracterizando-se através do "consumo de lugares" - a cultura, os recursos, o ambiente, a paisagem - tornando-se uma forma de descanso, status, conhecimento, entre tantas outras possibilidades subjetivas que o visitante sente no momento em que se desloca para locais que não são de sua residência habitual.

Esse turista carrega consigo uma herança cultural própria, cujo estilo de vida e costumes entram em contato com autóctones, podendo sofrer - e ocasionar - choques culturais em menor ou maior escala, dependendo do nível educacional, social, cultural, entre outros elementos. Nesse processo de trocas promovidas pelo turismo, o visitante é capaz de gerar uma série de consequências, desde ganhos econômicos para a localidade, até a descaracterização da paisagem, a perda da autenticidade cultural e a poluição do meio ambiente, entre outras. 
É crescente o número de indivíduos que se deslocam para participar de eventos, conhecer a cultura, a forma como o outro faz uso dos alimentos, entre outros motivos relacionados à arte gastronômica. Para muitos visitantes, se este momento estiver associado ao vinho, a experiência gastronômica estará completa!

Deslocar-se é uma prática que ocorre desde os primórdios. No entanto, os motivos que fazem com que os indivíduos viajem, transformam-se com as alterações vivenciadas pela sociedade. Viajar é um elemento dinâmico no próprio sentido da palavra, e além de tudo é dinâmico no seu significado com o passar das civilizações. O homem pré-histórico deslocava-se em busca de alimento e proteção, bem como no período do Renascimento as viagens tinham motivações culturais e de aprendizado.

E atualmente, o que leva realmente um indivíduo a deixar seu local habitual para conhecer outras regiões? Para conhecer a cidade ao lado ou o país que está há milhas de distância? O que o leva a ficar sujeito a imprevistos, intempéries, momentos que podem ser bons ou não, e que foi ou será pago, com dias e dias de trabalho?

A experiência turística é caracterizada por momentos da viagem que supõem inúmeras sensações e emoções vivenciadas pelo turista. Vivenciar momentos, experimentar as mais diversas sensações e guardar lembranças através de fotos, vídeos e memória são oportunidades que o indivíduo tem de consumir o atrativo turístico que lhe é oferecido numa viagem.

É na discussão a respeito do consumo que parte destas respostas podem ser encontradas, pois diferentes autores buscam na ação de consumir a solução para questões similares às supracitadas. Para autores como Baudrillard (1981) vivemos na chamada Sociedade de Consumo, enquanto Jensen (2002) chama de Sociedade do Sonho (JENSEN, 2002) e Lipovetsky (2007) caracteriza ainda como a Sociedade do Hiperconsumo. Este consumo exacerbado tem sua explicação na lógica econômica, pois para acumular capital e riqueza as empresas precisam comercializar um número cada vez maior de produtos.

A lógica capitalista é uma das explicações de Featherstone (1997) para o consumo. Além disso, o autor caracteriza o consumo como uma forma de distinção social, onde o indivíduo faz aquisições que identificam o seu poder financeiro. E numa terceira possibilidade, 
Feathersone sugere que o consumo faz parte de uma relação de troca com o esforço diário; é uma forma de recompensa pelo trabalho que o ser humano exerce.

O consumo, nos dias de hoje, não está ligado à satisfação de necessidades básicas como a fome, por exemplo, mas sim à satisfação da necessidade de conhecer a comida do outro, a forma como é servida e os novos sabores proporcionados. Para Lipovestky (2007), o sujeito está constantemente buscando algo que o leve a sair da rotina, pois não sabe conviver com ela. Adquirir bens materiais não é suficiente para atingir a tão sonhada felicidade e, assim, a busca direciona-se para elementos emocionais que proporcionem máxima satisfação.

Neste contexto, surge o conceito de Economia da Experiência (PINE; GILMORE, 1999), tendência oriunda da ciência econômica que tem se difundido em diferentes setores, inclusive no turismo. A essência do termo concentra-se na criação de experiências e emoções que o consumo de determinado produto propicia ao consumidor, oportunizando vivências individualizadas e, desta forma, singulares. O consumo de um produto satisfaz não apenas uma necessidade evidente, mas gera uma série de outras satisfações de âmbito subjetivo.

Para os autores mencionados, o consumidor não adquire simplesmente um produto ou serviço, mas paga "para passar algum tempo participando de uma série de eventos memoráveis" (PINE; GILMORE, 1999, p.2). Com isso, não se compra algo com o intuito de que este exerça simplesmente sua função, mas sim, que possibilite satisfazer outros desejos a ele relacionados.

Neste sentido, a aquisição de produtos turísticos denota uma série de emoções no turista, pois une sonho e fantasia no momento em que o turista realiza uma viagem e entra em contato com outras culturas, locais, pessoas. Este conjunto, associado a outros serviços, é comercializado no intuito de satisfazer algum tipo de necessidade, que na maioria das vezes caracteriza-se como subjetiva. Muitos são os motivos pelo qual um indivíduo decide fazer turismo: conhecimento, status, fuga da rotina, preenchimento do vazio. Podem estar relacionados a fatores externos, tais como política, cultura, economia, ou ainda pessoais, psicológicos, sociais (SWARBROOKE; HORNER, 2002).

Este consumo subjetivo é responsável por propiciar um resultado diferente quanto ao produto, pois cada consumidor associa o momento a uma rede de memórias e preferências individuais, 
que irão gerar emoções diversas. Para o visitante, a sensação de lazer e relaxamento, passa a ser vista como uma necessidade e não apenas um desejo. Por vezes, no momento da viagem, estas sensações são tidas como básicas pelo viajante. Assim, desejos e necessidades se confundem, incidindo no que Marcuse (1968) chama de falsas necessidades. Ou seja, a viagem não serve apenas como um deslocamento, mas também como forma de status, conhecimento, lazer, descanso, entre tantos outros simbolismos.

Baudrillard (1981) compartilha com as idéias de Marcuse, afirmando que os indivíduos não adquirem bens ou serviços apenas para satisfazer suas necessidades ou desejos. Acrescenta ainda que os consumidores compram uma série de elementos indicativos, possuidores de uma simbologia e representantes de um estilo, consumindo, desta forma, o que chama de signos.

Analisando as dificuldades mundiais e o modelo atual de produção e consumo, Viveret (2006, p.23) acredita que "o problema fundamental do ser humano não está do lado das necessidades, mas sim, no desejo, um elemento ilimitado por natureza". É, pois, a partir destes desejos humanos que Baudrillard (1981) considera os seres como parte criadora da Sociedade do Consumo. Interessante associar à discussão sobre consumo as idéias de Douglas e Isherwood (2004) que identificam que muitos dos bens consumidos são acessórios rituais, responsáveis por dar significado às situações e acontecimentos. As viagens são passíveis de serem ligadas ao termo, pois deslocamentos de férias tornaram-se um ritual nos dias de hoje, quase que uma prática obrigatória, que possui motivos diversos. Da mesma forma, estar à mesa também é um momento repleto de significados e, por vezes, torna-se um ritual.

De um lado, o consumidor/turista; do outro, os empreendedores que precisam de clientes para comercializar seu produto de maneira cada vez mais crescente. Assim, incentivar produtos turísticos associados às emoções tornou-se uma forma de agregar valor às viagens, buscando maior satisfação do turista e consequentemente incremento nas vendas. Fazer com que o visitante participe de maneira mais ativa nos destinos turísticos facilita a construção de significados sobre o produto, bem como, gera um número maior de experiências e momentos inesquecíveis, favorecendo a satisfação do turista.

Ao buscar esta proposta, os empreendimentos turísticos ficam diretamente ligados à necessidade de atrativos que propiciem diferentes sensações. A gastronomia e, como parte 
dela a produção de vinhos, devido a sua essência conceitual, tem a possibilidade de envolver o visitante em uma atmosfera onde todas as experiências são tidas como únicas: o aroma da uva e o sabor dos vinhos são tão específicos do terroir $^{3}$ quanto o modo de falar e o estilo de viver são próprios da localidade em questão. "Já pensou em colher cachos de uva no meio de parreirais? Ou, então, degustar vinho de olhos vendados e compartilhar as sensações e as lembranças que a experiência lhe faz sentir?" (SEBRAE, 2007, p.41).

Conforme afirma Beni (2007) faz-se necessário a interpretação do diferencial turístico de determinada região, estimulando a atenção, o olhar, o sentimento, a emoção, as sensações e as percepções dos turistas. Para que eles possam experimentar o que até então é ignorado ou passado despercebido, como as particularidades da paisagem e os aromas peculiares de um vinho.

\section{A Experiência do Enoturismo}

A oportunidade de viajar e explorar a gastronomia local através da degustação de pratos típicos elaborados com condimentos regionais e regados do saber-fazer de um povo torna-se atrativo para quem aprecia experiências gastronômicas. $\mathrm{O}$ ato de viajar em busca de alimentos e culturas diferentes vai além do simples fato de saciar a fome, pois relaciona-se a uma série de motivações intrínsecas ao visitante. É discutindo as motivações e hábitos culinários das pessoas que Sloan $(2005$, p.48) afirma que "o gosto gastronômico, ao que parece, não constitui uma expressão da preferência individual, e sim um indicador do desejo de aceitação social." Para complementar, cabe citar Bourdieu (2007), que defende que o gosto é caracterizado por uma apropriação material e simbólica relacionada a objetos e práticas que são passíveis de serem classificadas, criando formas e estilos de vida.

Baudrillard (2000), que analisa o consumo como algo simbólico, também contribui para a discussão gastronômica, pois considera que o alimento muitas vezes se converte em uma forma de consumo simbólico, cuja essência contempla não o objeto em sim, mas sim a relação (ou relações) que são estabelecidas com e através dele. A simbologia trazida com o alimento

\footnotetext{
${ }^{3} \mathrm{O}$ termo francês terroir está associado ao conjunto de solo, clima e exposição à luz que determinado espaço possui, tornando-o único e interferindo nas características do vinho produzido a partir das uvas ali cultivadas (CLARKE, 2002).
} 
se reflete em rituais, na religião, nas artes, na medicina, onde cada povo cria e propaga seus signos, que acabam por ser consumidos e vivenciados por indivíduos que não fazem parte de sua cultura, através das trocas proporcionadas pelo turismo. Na concepção de Schlüter (2003, p. 16):

O alimento não é simplesmente um objeto nutritivo que permite saciar a fome, mas algo que também tem um significado simbólico em uma determinada sociedade. Partindo de elementos similares, distintas culturas preparam sua alimentação de diversas formas. Essa variedade na preparação dos pratos está condicionada pelos valores culturais e códigos sociais em que as pessoas se desenvolvem.

É a esta infinita possibilidade de relações que o significado de um alimento propicia ao seu apreciador. Datas tradicionais para a preparação de determinado alimento, dias proibitivos de algum alimento no caso da liturgia, até mesmo a preparação de um jantar especial para receber amigos queridos são momentos que exemplificam sua significância. Para Gimenes (2009), o turista faz um consumo simbólico, pois consome também o contexto cultural em que se encontra e até mesmo a sensação de nostalgia.

Os alimentos são ordenados a partir de códigos de valores, regras e símbolos, em torno do qual determinado povo compartilha dos mesmos significados, acompanhando limites temporais e espaciais (GIARD, 1994 apud GIMENES, 2009). É a partir disso que nasce a gastronomia típica ou regional, como sendo "um conjunto de saberes-fazeres que engloba ingredientes, técnicas culinárias e receitas que são dispostas em um panorama relativamente coerente, delimitado geograficamente e passível de ser reconhecido como tal" (GIMENES, 2009, p.17). Relembrando Bourdieu (2007), no caso da gastronomia típica, o estilo de vida que classifica está vinculado a uma identidade regional, pois o prato típico expressa identidade e pertencimento a um determinado povo.

Corner (2006) enfatiza que a experiência de degustar um prato próprio do lugar proporciona ao turista experiências inesquecíveis, marcantes, que vão representar muito mais que um simples souvenir. A autora complementa:

A cozinha é um símbolo cultural, é memória, e principalmente patrimônio cultural de qualquer grupo social. A simbologia dos alimentos exerce uma influência ao homem, podendo constituir-se em importante elemento que revela identidades e ajuda a entender a cultura de um povo. (CORNER, 2006, p. 2). 
Como parte do interesse das pessoas pela gastronomia, James (1996 apud SLOAN, 2005) acredita que o mundo está redescobrindo ou reinventando tradições em termos de comida. Nessa busca, o indivíduo está retornando para situações que foram excluídas do dia-a-dia, como é o caso daqueles que compram produto direto dos produtores locais, o que o autor caracteriza como uma nostalgia rústica. É essa nostalgia que muitas vezes está presente nas sensações que o turista vivencia ao deslocar-se para regiões que exploram a gastronomia típica.

A gastronomia que hoje é considerada uma arte e depende de vários fatores sejam geográficos como: clima, costa, rios, tipo de solo, chuvas, produção agrícola, ou fatores históricos como: os costumes alimentares introduzidos pelos colonizadores, ou ainda por imigrantes e migrantes que incorporam seus costumes aos da terra que os acolhe e vice-versa (CORNER, 2006). Portanto, a gastronomia é tida como relevante e possui um importante papel a desempenhar no turismo de cunho cultural. Ao abordar o tema gastronomia, uma série de elementos pode estar presente, como é o caso do vinho. Esta bebida, resultado da fermentação da uva, faz parte do convívio humano desde a antiguidade. Para gregos e romanos o vinho era motivo de festas e rituais aos deuses Dionísio e Baco (FLANDRIN; MONTANARI, 1998). Atualmente também faz parte de festivais e roteiros, promovendo um fluxo considerável de pessoas em diferentes regiões do mundo. Estes deslocamentos fazem parte do enoturismo, tipologia caracterizada pela visitação aos vinhedos, cantinas e festivais vinícolas, por aqueles que se interessam pela uva, pelo vinho e pelas mais diversas características de uma região vitivinícola, sejam elas naturais ou culturais (HALL; MACIONIS, 1998).

O enoturismo está caracterizado como um sistema centrado na experiência enoturística, que influencia e sofre influência de aspectos individuais do visitante e da oferta como um todo. Assim sendo, a demanda é diferente de um turista para outro, de acordo com aspectos culturais e é formada pela percepção, uma união entre experiência passada, informação e preferências. Estas, combinadas com motivações específicas, criam uma expectativa e também uma imagem quanto à destinação turística (TONINI, 2007).

Para melhor desenvolver a atividade enoturística e adequar a oferta aos desejos e interesses do visitante, os empreendimentos vitivinícolas criam rotas com atrativos definidos - visitação, 
degustação, pratos típicos, contato com moradores e cultura local, entre outros transformando a região em si em um produto turístico. Diferentes pesquisas apontam o vinho como o principal motivo da viagem para conhecer rotas enoturísticas. No entanto, identificam também uma série de outros atrativos secundários, entre eles, entretenimento, encontros com os produtores, possibilidade de desfrutar outros aspectos da região vitivinícola, como a paisagem e a tranquilidade (LAVANDOSKI, 2008). Estes últimos, embora subjetivos e abstratos, são características associadas à localidade turística e conferem um significado compartilhado pelos visitantes.

Como o vinho faz parte da cultura de alguns povos e consequentemente de sua gastronomia, torna-se difícil não associar os dois durante a realização de viagens desse segmento. Schlüter (2003) aponta inúmeras semelhanças entre o turismo gastronômico e o enoturismo, entre elas, o fato de valorizarem a tradição e preservação do patrimônio histórico e cultural, possuir forte ligação com o setor primário e estar comumente localizado em áreas rurais. Os turistas gastronômicos e os enoturistas são visitantes que possuem algum entendimento sobre o tema, buscando através das viagens aumentarem seus conhecimentos e desfrutar ao máximo do motivo que os levou ao deslocamento. No caso do enoturista, embora seja a degustação do vinho e toda a experiência envolvente que motive o deslocamento, é comum o visitante buscar o contato com a gastronomia local. Tanto o turismo gastronômico quanto o enoturismo, portanto, "consomem localidades" e propiciam uma economia voltada para as sensações e experiências.

\section{Experiência Enogastronômica no Vale dos Vinhedos}

Identificar sensações ao se deparar com uma paisagem vitivinícola e ao degustar um vinho, e assim, caracterizá-las como um consumo de experiências únicas foi o propósito da investigação, de caráter exploratório, com os turistas do Vale dos Vinhedos. A região, fruto da imigração italiana do século XIX, é pioneira no desenvolvimento do enoturismo no país, que iniciou a partir de ações individuais de pequenos produtores, descontentes com o mercado da uva na década de 1990. O Vale dos Vinhedos recebe anualmente em torno de 150 mil visitantes de diferentes estados e também estrangeiros (APROVALE, 2009). 
A pesquisa foi aplicada nos finais de semana dos meses de janeiro e fevereiro de 2010, período de colheita da uva na região do Vale dos Vinhedos. Do universo de 120 questionários preenchidos, 9 foram descartados: um devido à idade (abaixo de 18 anos, cuja legislação não permite comercialização de bebida alcoólica) e 8 visitantes residentes no município de Bento Gonçalves. Desta forma, a amostragem foi composta de 111 respondentes, com idades entre 18 e 63 anos, compreendendo exclusivamente turistas do Vale dos Vinhedos.

Quando questionados sobre o motivo pelo qual viajam (Tabela 1), 23\% responderam para lazer e entretenimento. As demais respostas dividiram-se entre combinações com lazer, conhecimento, cultura, descanso, status, visita a amigos e parentes e negócios. A associação da prática do turismo como uma forma de lazer fica mais visível através da pesquisa, pois a motivação principal está, na maioria das vezes, relacionada ao lazer. Houve uma transformação dos fatores que levam às viagens, quando se olha para as características dos deslocamentos no passar dos séculos.

Tabela1: Motivo pelo qual viajam

\begin{tabular}{c|c}
\hline Motivos & Porcentagem \\
\hline Lazer/entretenimento & $23 \%$ \\
Lazer e conhecimento & $7 \%$ \\
Lazer e cultura & $7 \%$ \\
Lazer, cultura e conhecimento & $7 \%$ \\
Lazer e amigos & $5 \%$ \\
Lazer e negócios & $5 \%$ \\
Negócios & $4 \%$ \\
Lazer, cultura e Descanso & $4 \%$ \\
Outras combinações & $38 \%$ \\
\hline Total & $100 \%$ \\
\hline
\end{tabular}

Com relação aos sentimentos dos entrevistados ao viajar, percebe-se que "satisfação" foi o sentimento mais apontado pelos turistas. Em números pouco expressivos, as demais respostas foram combinações entre satisfação, prazer, alegria, euforia, tranqüilidade, ansiedade, novas 
culturas. Nenhuma das opções negativas foi assinalada, como: tristeza, medo, insegurança, culpa, desconforto. Segundo historiadores, os deslocamentos do passado eram permeados pela insegurança e desconforto, características que não fazem parte das viagens da atualidade. Satisfação, alegria, tranquilidade, prazer, são sentimentos positivos e motivadores do número crescente de viajantes pelo mundo. Essa busca constante pela satisfação de alguma necessidade durante o ato de consumir também mostra-se através destas respostas. Ao sentirem satisfação, os visitantes estão atestando que o produto/serviço consumido está de acordo com as expectativas geradas.

Com o objetivo de identificar o que a amostragem da pesquisa considera ser uma viagem de experiência prazerosa, foram disponibilizadas as seguintes opções: preferências pessoais, qualidade dos atrativos, qualidade nos serviços, qualidade da infraestutrura turística e outro. A maioria dos turistas, $27 \%$ consideram que todos os indicados são responsáveis para uma experiência prazerosa. Os aspectos pessoais foram citados por $13 \%$, enquanto $11 \%$ assinalaram apenas a qualidade dos atrativos e 10\% acreditam que a qualidade do serviço associada à qualidade dos atrativos é suficiente. Para um número pouco expressivo, $7 \%$ dos entrevistados, qualidade dos atrativos, dos serviços e infraestrutura turística foram assinaladas e para $5 \%$, somente a qualidade de serviço pode fazer a diferença. Os demais respondentes, $27 \%$, assinalaram combinações entre as opções listadas acima.

Considerando que a maioria dos entrevistados viaja por lazer e busca sentimentos de prazer e satisfação durante suas viagens, para que esta busca se concretize deve-se dar atenção a uma série de fatores presentes no destino turístico. Assim, a qualidade dos atrativos, dos serviços e da infraestrutura deve ser direcionada ao bem-estar do visitante. Em contrapartida, este mesmo visitante deve realizar uma viagem que venha ao encontro de suas preferências pessoais, pois, se seu interesse é descansar, provavelmente não ficará satisfeito em viajar para uma praia badalada. O turista possui grande parte da responsabilidade quanto à satisfação das necessidades através da prática do turismo.

Com relação ao principal motivo para o deslocamento até o Vale, 37 (33\%) responderam o vinho e as vinícolas, 31 (28\%) viajaram para conhecer a região e fazer turismo. Fatores pessoais como a proximidade com outras regiões e apresentar a região para amigos e familiares representaram $10 \%$ da amostragem. Do total dos pesquisados, $5 \%$ vieram em 
função das belezas da região e o mesmo número (5\%) devido à cultura local. Em menor número, estão os motivos relacionados às recordações, aos negócios, por ser um passeio agradável ou maravilhoso, através de indicação e propaganda, além da gastronomia.

Sobre o diferencial que a região do Vale dos Vinhedos apresenta perante demais regiões de características similares, $15 \%$ afirmaram ser a organização e infra-estrutura o ponto forte. Os vinhos e/ou a qualidade dos mesmos foram apontadas por $10 \%$ e também $10 \%$ identificaram como diferencial o atendimento/serviço. Para somente 1\% dos entrevistados, a gastronomia é um diferencial do Vale, apesar de $32 \%$ dos entrevistados não terem respondido a questão.

Pode-se perceber que o vinho/vinícola é apontado por um grande número de entrevistados como diferencial do Vale, além de ser o principal fator motivador das viagens para a região, o que caracteriza a tipologia enoturismo. Por outro lado, a gastronomia não foi referenciada, no entanto, conforme abordado no referencial teórico, o vinho é um elemento que faz parte da gastronomia, principalmente quando se refere à gastronomia regional e pratos típicos.

Porém, o turista se confunde com a relação existente entre o vinho e a gastronomia, fato este que pôde ser comprovado quando questionados se a existência da gastronomia italiana é um motivo para o deslocamento ao Vale, onde $64 \%$ dos turistas entrevistados responderam que sim. Este resultado confronta as respostas vistas acima, mas cabe salientar que para os visitantes, a gastronomia não é o motivo principal, no entanto, é um fator motivacional para as viagens ao Vale dos Vinhedos. Cada vinícola realiza seu trabalho de divulgação, que se soma à divulgação da rota Vale dos Vinhedos como um todo. O nome da rota por si só deixa transparecer o tipo de atrativo que possui. Assim, os turistas sabem de antemão o que irão conhecer e se irá ao encontro do que buscam na viagem. Se as vinícolas não existissem, provavelmente seria necessário outro tipo de direcionamento e marketing para que os turistas viessem à região motivados exclusivamente pela gastronomia típica italiana.

Descobrindo qual a sensação ao se deparar com a paisagem do Vale dos Vinhedos (Tabela 2), tem-se que $23 \%$ responderam sentir alegria, felicidade e euforia. Já $16 \%$ responderam sentir prazer. Outros sentimentos foram registrados, porém em menor quantidade. 
Tabela 2: Sensação ao deparar com a paisagem do Vale dos Vinhedos

\begin{tabular}{c|c}
\hline Sensação & Porcentagem \\
\hline Alegria/felicidade/euforia & $23 \%$ \\
Prazer & $16 \%$ \\
Emoção & $11 \%$ \\
Satisfação & $10 \%$ \\
Tranquilidade/paz & $2 \%$ \\
Admiração & $1 \%$ \\
Não responderam & $37 \%$ \\
\hline Total & $100 \%$ \\
\hline
\end{tabular}

Os entrevistados foram questionados sobre qual a sensação durante uma degustação de vinhos no Vale dos Vinhedos. As sensações foram agrupadas para uma melhor análise (Tabela 3). Dos entrevistados, $15 \%$ não responderam a questão por não terem feito a degustação por motivos diversos, tais como o fato de estarem dirigindo.

Tabela 3: Sensações ao degustar um vinho no Vale dos Vinhedos

\begin{tabular}{c|c}
\hline Sensações & Porcentagem \\
\hline Maravilhosa/excelente/única/sensacional/a melhor/uma delícia & $33 \%$ \\
Prazer/satisfação/alegria/privilégio & $32 \%$ \\
Não responderam & $15 \%$ \\
Boa & $6 \%$ \\
Diferente & $5 \%$ \\
De estar nos parreirais & $5 \%$ \\
Emoção & $2 \%$ \\
Algo vivo & $1 \%$ \\
Degustar cultura & $1 \%$ \\
\hline Total & $100 \%$ \\
\hline
\end{tabular}

Conforme apontado, nenhum dos respondentes caracterizou a experiência da degustação como algo negativo. O mesmo ocorreu com as sensações ao se deparar com a paisagem. Dessa forma, as relações com o meio, seja no seu aspecto natural ou cultural, influenciam as 
sensações do turista no momento da degustação. Quando as primeiras vinícolas do Vale abriram seu espaço para receber visitantes na década de 90, a prática de degustar o vinho era parte do ritual de bem acolher. Consequentemente, neste mesmo momento ocorria à venda dos produtos para estes visitantes. Com o tempo, a degustação tornou-se uma prática comum nas vinícolas como forma de facilitar a comercialização e, nos últimos anos, alguns fabricantes adotaram a cobrança de uma taxa para que o visitante possa realizá-la.

Ao serem questionados sobre a opção de escolher entre o Vale e outras regiões vinícolas no Brasil ou no mundo, 63\% afirmaram que optariam por conhecer primeiramente o Vale dos Vinhedos frente a outros destinos similares. A maior parte dos entrevistados (73\%) não conhece outro local igual ou similar ao Vale, onde se possam vivenciar as mesmas experiências. Os que conhecem (27\%) apontaram locais no país e também no exterior como Chile, França, Portugal, EUA, Itália. Pode-se inferir que para os turistas que conhecem outros locais vitivinícolas, a experiência no Vale não é considerada única.

Assim, a discussão acerca do que é uma experiência única não cabe na atividade turística, visto que isto depende do histórico de cada um, suas preferências e limitações. Portanto, de modo geral, toda experiência é única e ocorre apenas no interior do indivíduo, no seu íntimo, não sendo passível de ser comercializada como um sentimento que é vendido na prateleira do supermercado mais próximo.

Do total de entrevistados, 92\% acreditam estar "consumindo" emoções quando estão no Vale, perante $8 \%$ que não consideraram o consumo de emoções nas atividades realizadas na região. O turista mostra-se ciente de que este consumo vai além do aspecto material, pois o visitante não busca o Vale apenas para adquirir vinhos de qualidade, mas também no intuito de satisfazer suas falsas necessidades (MARCUSE, 1968).

Finalizando os questionamentos, os turistas foram desafiados a definir com apenas uma palavra a experiência de estar no Vale dos Vinhedos (Tabela 4). Os resultados obtidos foram agrupados conforme a tabela abaixo: 
Tabela 4: Experiência de estar no Vale dos Vinhedos

\begin{tabular}{|c|c|}
\hline Palavras & Porcentagem \\
\hline Sensacional/inesquecível/única/apaixonante/gratificante & $36 \%$ \\
\hline Prazer/satisfação/felicidade/realização & $21 \%$ \\
\hline Paz/tranquilidade/bem-estar/agradável & $14 \%$ \\
\hline Emoção & $10 \%$ \\
\hline Cultura/patrimônio/aprendizado & $7 \%$ \\
\hline Viver & $3 \%$ \\
\hline Vinho/qualidade & $2 \%$ \\
\hline Bêbado & $1 \%$ \\
\hline Indefinível & $1 \%$ \\
\hline Sonhar & $1 \%$ \\
\hline Elegância & $1 \%$ \\
\hline Surpresa & $1 \%$ \\
\hline Dinheiro & $1 \%$ \\
\hline Natureza & $1 \%$ \\
\hline Total & $100 \%$ \\
\hline
\end{tabular}

Em pesquisa anterior (LAVANDOSKI, 2008), também foram identificadas sensações agradáveis e sentimento de realização pessoal com relação à experiência vivida durante as atividades propiciadas no Vale dos Vinhedos. A associação com paz e tranquilidade é, por vezes, decorrente de uma paisagem rural onde há menos movimentação do que nos centros urbanos. Durante as entrevistas, muitos foram os momentos em que os turistas relacionaram sua vinda ao Vale, ao fato de possuírem descendência italiana, o que está ligado ao sentimento de emoção. A partir do motivo que faz com que o turista viaje, o mesmo cria expectativas acerca do local, que pode ir ao encontro do que o destino turístico é capaz de proporcionar. As respostas identificadas fazem parte do resultado entre motivação, expectativas e experiência vivida. 


\section{Conclusão}

Experimentar, não importa o que, é vivenciar constantemente emoções. Vive-se um período em que a realidade confunde-se com a ilusão e saber diferenciar uma da outra não parece ser tão importante quanto o prazer proporcionado por diferentes formas de consumir emoções.

Através da pesquisa realizada, foi possível identificar que as viagens realizadas no Vale dos Vinhedos equivalem a momentos repletos de sensações. A sensação do encontro com a paisagem, o sentimento de estar degustando um vinho em vinícolas cujo conhecimento passa de geração para geração, o momento de fartar-se com um prato típico italiano são experiências proporcionadas para estes turistas, neste local.

Cabe salientar que praticamente todos os sentimentos relatados na pesquisa estão vinculados a algo positivo, a uma sensação agradável e satisfatória. Embora o elemento gastronomia não tenha sido um item enaltecido pelos respondentes, o vinho é, de fato, o principal motivador destes deslocamentos. Conforme visto na revisão bibliográfica, a bebida faz parte da gastronomia de um povo e, assim sendo, podemos inferir que os visitantes vêem ao Vale dos Vinhedos em busca dos prazeres advindos de elementos da gastronomia típica italiana, cujo vinho faz parte, sendo traço marcante da cultura da região.

Conhecer o outro e suas diferenças inclusive na forma de alimentar-se é algo que pode ocorrer de modo natural, com ou sem choques culturais. No entanto, na atualidade existe um engajamento dos envolvidos no setor turístico em prol de incentivar os deslocamentos no intuito de gerar divisas. Incitar desejos e necessidades torna-se fundamental e associar oportunidades de prazer ao contato com a gastronomia típica tem trazido resultados positivos quando o objetivo é econômico. Muito além, propicia orgulho àquele que trabalha com a terra e oportuniza a valorização de características que outrora foram proibidas ou perdidas no país, como o fato de falar o dialeto italiano e vestir-se com trajes típicos.

Valorizar a identidade local, os atrativos e o que faz parte da história são aspectos capazes de proporcionar aos visitantes uma experiência que vai além do fato de conhecer um novo ambiente. É uma experiência que transcende diferenças em busca da satisfação de necessidades do indivíduo na atualidade. Necessidades estas que envolvem o gosto e suas 
particularidades em um mundo tão homogêneo, no sentido de produtos e serviços padronizados.

\section{Referências}

APROVALE. Material fornecido pela Assessoria de Imprensa. Bento Gonçalves, 2009.

BAUDRILLARD, Jean. A sociedade de consumo. Lisboa: Edições 70, 1981.

. O sistema dos objetos. São Paulo: Perspectiva, 2000.

BENI, Mário C. Análise estrutural do turismo. 12 ed. São Paulo: Editora SENAC, 2007.

BOURDIEU, Pierre. A distinção: crítica social do julgamento. São Paulo: Edusp, 2007.

CLARKE, Oz. Oz Clarke's Wine Atlas: wines and wine regions of the world's great vineyard areas. 2 ed. London: Little Brown, 2002.

CORNER, Dolores M. R. A gastronomia como atrativo no turismo cultural. IV Seminário em Pesquisa de Turismo do MERCOSUL. Caxias do Sul, jul. 2006.

DOUGLAS, Mary. ISHERWOOD, Baron. O mundo dos bens: para uma antropologia do consumo. Rio de Janeiro: UFRJ, 2004.

FEATHERSTONE, Mike. Cultura de consumo e pós-modernismo. São Paulo: Studio Nobel, 1997.

FLANDRIN, Jean-Louis; e MONTANARI, Massimo. História da alimentação. Tradução de Luciano Vieira Machado e Guilherme J. F. Teixeira. São Paulo: Estação Liberdade, 1998.

GIMENES, Maria Henriqueta Sperandio Garcia. O uso turístico das comidas tradicionais: algumas reflexões a partir do Barreado, prato típico do litoral paranaense (Brasil). Turismo \& Sociedade. Curitiba, v.2, n.1, 2009, p.8-24.

HALL, C. Michael. MACIONIS, Niki. Wine tourism in Australia and new in rural areas. New York: John Wiley \& Sons, 1998.

JENSEN, Rolf. The dream society 2: heartstorm. JP Boger, 2002.

LAVANDOSKI, Joice. A paisagem na Rota Enoturística Vale dos Vinhedos (RS), na perspectiva do visitante. Dissertação (Mestrado em Turismo). Universidade de Caxias do Sul. Caxias do Sul, 2008.

LIPOVETSKY, Gilles. A felicidade paradoxal: ensaio sobre a sociedade do hiperconsumo. São Paulo: Companhia das Letras, 2007.

MARCUSE, Herbert. A ideologia da sociedade industrial. Rio de Janeiro: Jorge Zahar, 1968.

PINE II, Joseph; GILMORE, James H. O espetáculo dos negócios: desperte emoções que seduzam os clientes, sensações intensas determinam o valor de produtos e serviços. 2 ed. Rio de Janeiro: Elsevier, 1999.

SCHLÜTER, Regina. Gastronomia e turismo. Tradução de Roberto Sperling. São Paulo: Aleph, 2003.

SEBRAE. Vinhos brasileiros: o mundo degusta o Brasil. Brasília: Athalaia, 2007.

SLOAN, Donald. Gastronomia, restaurantes e comportamento do consumidor. Barueri: Manole, 2005. 
SWARBROOKE, John. HORNER, Susan. O comportamento do consumidor no turismo. São Paulo: Aleph, 2002.

TONINI, Hernanda. Estado e turismo: políticas públicas e enoturismo no Vale dos Vinhedos. Dissertação (Mestrado em Turismo). Universidade de Caxias do Sul. Caxias do Sul, 2007.

VIVERET, Patrick. Reconsiderar a riqueza. Tradução Vera Ribeiro. Brasília: Editora Universidade de Brasília, 2006.

Recebido em: 27/07/2010

Aprovado em: 09/11/2010 